\title{
Neonatal Myocardial Infarction or Myocarditis?
}

\author{
Leanne de Vetten $\cdot$ Klasien A. Bergman • \\ Nynke J. Elzenga $\cdot$ Joost P. van Melle $\cdot$ \\ Albertus Timmer $\cdot$ Beatrijs Bartelds
}

Received: 8 September 2010/Accepted: 7 December 2010/Published online: 8 January 2011

(C) The Author(s) 2011. This article is published with open access at Springerlink.com

\begin{abstract}
We report a 29 week-gestation preterm infant who presented during his second week of life with cardiogenic shock. Clinical presentation and first diagnostics suggested myocardial infarction, but echocardiographic features during follow-up pointed to a diagnosis of enteroviral myocarditis. The child died of chronic heart failure at 9 months of age. Autopsy showed passed myocardial infarction. No signs for active myocarditis were found. We discuss the difficulties in differentiating between neonatal myocardial infarction and myocarditis. Recognizing enteroviral myocarditis as cause for cardiogenic shock is of importance because of the therapeutic options.
\end{abstract}

Keywords Myocardial infarction $\cdot$ Myocarditis $\cdot$ Neonate

Neonatal myocardial infarction (MI) is a rare occurrence and mostly associated with congenital heart disease, abnormal coronary arteries, or thromboembolic events. We present a preterm neonate with cardiac failure due to myocardial

L. de Vetten $(\bowtie) \cdot$ K. A. Bergman

Department of Neonatology, University Medical Centre

Groningen, Hanzeplein 1, P. O. Box 30.001, 9700 RB

Groningen, The Netherlands

e-mail: 1.de.vetten@isala.nl

N. J. Elzenga $\cdot$ J. P. van Melle $\cdot$ B. Bartelds

Centre for Congenital Heart Disease, University Medical Centre

Groningen, Groningen, The Netherlands

A. Timmer

Department of Pathology and Medical Biology, University

Medical Centre Groningen, Groningen, The Netherlands

L. de Vetten

Department of Paediatrics, Isala Klinieken, Location Sophia

Hospital, P. O. Box 10400, 8000 Zwolle, The Netherlands ischemia. Diagnostic findings suggested enteroviral myocarditis as the precipitating condition. We discuss the differentiation and possible association between neonatal MI and myocarditis, referring to several medical databases (Cochrane, Sumsearch, Trip, and Pubmed).

\section{Case Report}

Baby A

Baby A. was born preterm at $29+3$ weeks' gestation by spontaneous vaginal delivery after an uncomplicated pregnancy to a healthy 33-year-old G2P1 mother. His birth weight was $1650 \mathrm{~g}$ (90th percentile). He required ventilatory support and surfactant for infant respiratory distress syndrome. An umbilical artery catheter was in site for a couple of days to monitoring blood pressure, and no umbilical venous catheter was inserted during admission. The further course was uneventful, and on day 8 he was transferred to a local hospital.

Within 1 day, patient was readmitted to our neonatal intensive care unit because of suspected septicaemia and cardiac arrhythmias. He exhibited alternating tachycardia and bradycardia with a mean blood pressure of $33 \mathrm{~mm} \mathrm{Hg}$, weak peripheral pulses, and prolonged capillary refill. He showed mild respiratory distress, grunting, and oxygen saturation of $90 \%$ in room air. There was no heart murmur; the lungs were clear on auscultation; and the abdomen was soft without hepatosplenomegaly.

Circulatory support was given by intravenous fluids. Antibiotics were started for suspected septicaemia. Blood cultures remained negative, but rectal and sputum cultures were positive for Coxsackie B III virus. Chest X-ray showed no significant abnormalities. An electrocardiogram revealed 
ST-depression in right precordial leads and aVR, and ST elevation in I and II (Fig. 1) Laboratory data showed increased cardiac enzymes consistent with myocardial damage (Table 1). Echocardiography revealed left-ventricular dysfunction with a severely hypokinetic posterolateral wall, a hyperkinetic septum, and some pericardial effusion. Abnormal coronary anatomy as cause of MI was excluded. No sources for thromboemboli were found by echography, and clotting studies showed no abnormalities.

Respiratory distress increased, and mechanical ventilation was instituted. Circulatory support consisted of inotropics, diuretic therapy, and milrinone, which was later switched to captopril. The course was complicated by necrotizing enterocolitis, which was managed with antibiotics and parental nutrition. After 11 weeks of hospitalization, the patient was discharged home, still requiring nasogastric tube feeding and medication for chronic heart failure (diuretics, beta blocker, ACE inhibitor). During the following months, echocardiographic follow-up showed a persisting pattern of decreased left-ventricular function with increased right ventricle pressure. No compensatory hypertrophy of noninfarcted regions was seen. Instead, global impairment of ventricular function was found, suggesting post-myocarditis cardiomyopathy rather than remodeling after myocardial infarction. Within 5 months, progressive left-ventricle dilatation became apparent together with suprasystemic pressure in the right ventricle. We attempted to evaluate the patient for possible heart transplantation. During this admission, heart function deteriorated, and at the age of 9 months he died from progressive and medication-resistant heart failure. Autopsy revealed increased heart weight $(80 \mathrm{~g}$ [expected weight for length $=42 \mathrm{~g}]$ ).

At autopsy, intracardiac anatomy was normal as was the origin and anatomy of the coronary arteries. The lumen of the coronary arteries was patent. Microscopy of the coronary arteries showed focal intima hyperplasia, a universal response of blood vessels to injury. Furthermore, microscopy showed global subendocardial fibroelastosis with scar tissue in the lateral wall of the left ventricle, including the papillary muscles, associated with loss of myocytes and hypertrophy of residual myocytes (Figs. 2, 3). There were no signs of active myocarditis. The wall of the right ventricle was thickened, and the pulmonary trunk was dilated. Microscopy of both lungs demonstrated alveolar and septal hemorrhage as well as hemosiderophages as a sign of longstanding venous congestion due to left-ventricular failure. (Fig. 3). Signs of (primary) pulmonary arterial hypertension were not present.

\section{Discussion}

Baby A. was readmitted with the clinical presentation of cardiac shock and arrhythmias. Myocardial infarction was diagnosed based on the acute onset of symptoms and the results of laboratory tests, electrocardiography (ECG), and echocardiography. Yet findings at follow-up echocardiography suggested myocarditis. We will discuss possible association, diagnostics, therapy, and prognosis of both disorders.
Fig. 1 ECG in baby A at first presentation

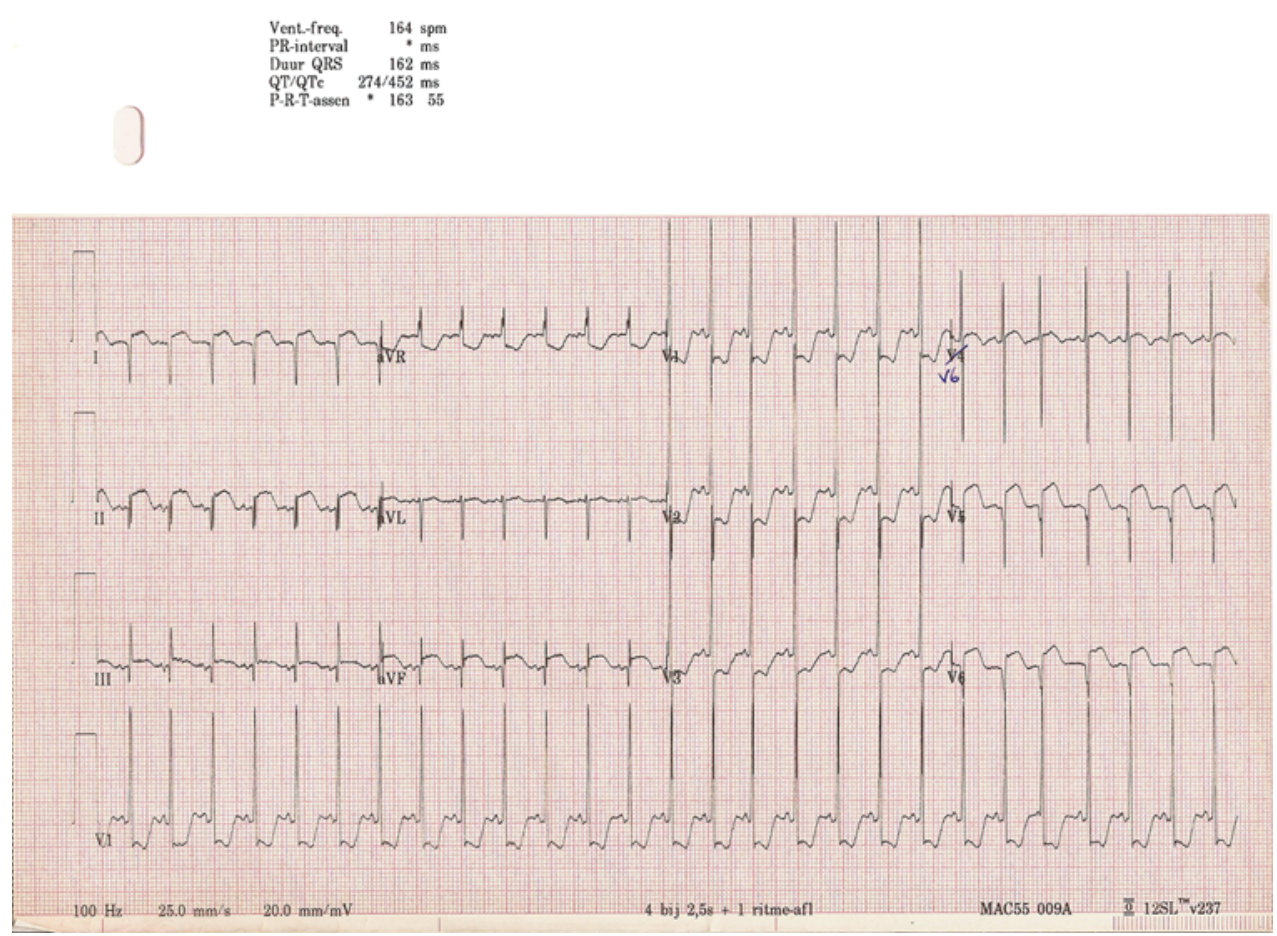


Table 1 Serial cardiac enzymes in baby A

\begin{tabular}{lllllll}
\hline Enzyme & \multicolumn{2}{l}{ Enzyme level } & & Normal \\
\cline { 2 - 5 } & $\mathrm{t}=0$ (onset) & $\mathrm{t}=12 \mathrm{~h}$ & $\mathrm{t}=24 \mathrm{~h}$ & $\mathrm{t}=48 \mathrm{~h}$ & $\mathrm{t}=240 \mathrm{~h}$ & \\
\hline CK $(\mathrm{U} / \mathrm{l})$ & 1345 & 1826 & 1322 & 667 & 34 & $0-200$ \\
CK-MB (U/l) & 225 & 318 & 186 & 118 & 19 & 0 \\
As \% of CK & 17 & 17 & 14 & 18 & 55 & $<4$ \\
LDH (U/l) & 975 & 1310 & 1367 & 1127 & 331 & $<250$ \\
ASAT $(\mathrm{U} / \mathrm{l})$ & 223 & 335 & 321 & 205 & 18 & $<40$ \\
Troponine-T $(\mu \mathrm{g} / \mathrm{l})$ & 4.84 & 6.52 & 8.07 & 4.06 & 0.5 & $<0.03$ \\
\hline
\end{tabular}

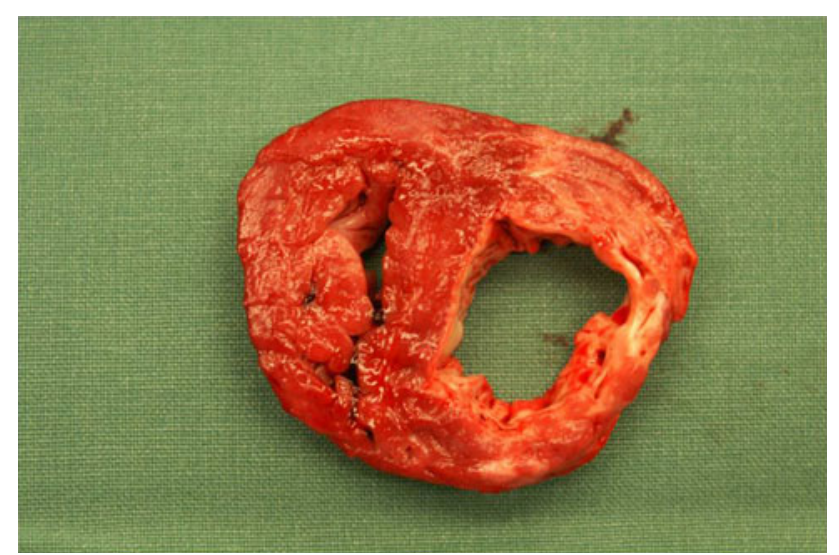

Fig. 2 Fibrosis in the postlateral wall of dilated left ventricle with hypertrophy of right ventricle and septum

\section{Possible Association}

MI in neonates is rare but has been described in cases of congenital heart disease, abnormal coronary arteries, thromboembolic events, and perinatal asphyxia (Table 2). Furthermore, several cases of neonatal MI in the presence of enteroviral myocarditis have been reported (Table 3). Association might be coincidental because enteroviral infections are common, and the course often subclinical. However, enteroviral myocarditis might mimic MI by producing similar diagnostic findings [21]. Otherwise, myocarditis might precipitate MI in susceptible subjects. Postulated mechanisms include coronary thrombosis, coronary artery spasm, coronary artery embolism, and large-vessel and microvascular coronary arteritis $[9,15]$. In a case of neonatal enteroviral myocarditis, occlusion of the left circumflex coronary artery was found by cardiac catheterization [13]. Another case report of neonatal myocarditis shows a fixed perfusion defect of the myocardium on technetium-99 scan [15]. Finally, an autopsy in a young woman who died from myocarditis showed thrombotic occlusion of a coronary artery and MI in its vascular territory [23]. These findings support the theory that MI might present as a complication of enteroviral myocarditis.

\section{Diagnostic Findings}

Clinical presentation and diagnostic findings of neonatal MI and myocarditis are similar. Clinical presentation of cardiac dysfunction in a neonate is nonspecific and includes poor feeding, dyspnoea, and shock. Findings highly associated with cardiac disease are cyanosis, hypotension, friction rub, and arrhythmia. Reich et al. [26]. described ECG criteria that can be used for diagnosing MI in children (Table 4). However, similar ECG abnormalities may occur in myocarditis $[15,21]$. Increased cardiac enzymes are indicative for myocardial damage but occur in MI as well as in myocarditis [15, 21]. ECG is important in ruling out congenital heart disease and abnormalities of the coronary arteries. Regional wall-motion abnormalities can indicate local myocardial ischemia, but they have been described in myocarditis as well $[13,21]$. Follow-up echocardiography
Fig. 3 Left panel Postlateral wall of the left ventricle with scar tissue (blue) and residual myocytes (Masson staining $[20 \times])$. Right panel Lung with alveolar and septal hemosiderophages (blue), consistent with venous congestion (Prussian Blue staining $[100 \times])$
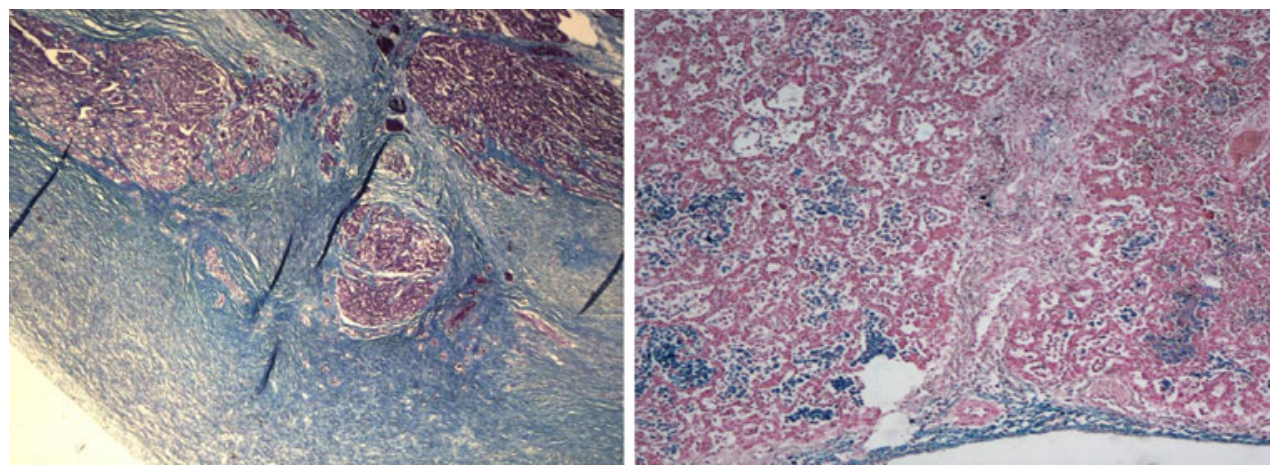
Table 2 Previous case reports of neonatal MI

\begin{tabular}{|c|c|c|c|c|c|}
\hline \multicolumn{3}{|l|}{ Proven MI } & \multicolumn{3}{|c|}{ MI suggested by laboratory, ECG, and echocadiogram findings } \\
\hline Investigator & Diagnosis & Outcome & Investigator & Diagnosis & Outcome \\
\hline Ferns [11] & Thrombus & Survived & Ferns $[11]$ & $3 \times$ unclear & $3 \times$ survived \\
\hline Takeuchi [31] & Thrombus & Died & Saker [27] & Unclear & Survived \\
\hline Murugan [24] & Thrombus & Died & Tometzki [33] & Unclear & Survived \\
\hline Tilett [32] & Thrombus & Died & Hruda $[16]$ & Unclear & Survived \\
\hline Abdurrahman [1] & Thrombus & Died & Boulton [8] & Unclear & Survived \\
\hline Lucas [22] & Thrombus & Died & Baldew [4] & Unclear & Survived \\
\hline Boulton [8] & Thrombus & Survived & Kilbride [20] & Unclear & Survived \\
\hline Bernstein [6] & Thrombus & Died & Fagan $[10]$ & Unclear & Survived \\
\hline Sandhyamani [28] & $4 \times$ asphyxia & $4 \times$ died & & & \\
\hline Kilbride [20] & Asphyxia & Died & & & \\
\hline Sapire [29] & Thrombus & Died & & & \\
\hline Iannone [18] & Asphyxia & Died & & & \\
\hline Fletcher [12] & Thrombus & Died & & & \\
\hline Berry [7] & Thrombus & Died & & & \\
\hline Arthur [3 ] & Thrombus & Died & & & \\
\hline Van der Hauwert [34] & Thrombus & Died & & & \\
\hline Gault [14] & Asphyxia & Died & & & \\
\hline Subtotal & $18 / 20$ died & & $0 / 10$ died & & \\
\hline Total & 18/30 died & & & & \\
\hline
\end{tabular}

Table 3 Previous case reports of neonatal myocarditis

\begin{tabular}{|c|c|c|c|}
\hline Investigator & Diagnosis & Outcome & MI suggested? \\
\hline Nathan [25] & Enterovirus & Survived & No \\
\hline Inwald [19] & $7 \times$ enterovirus & $\begin{array}{l}4 \times \text { survived } \\
3 \times \text { died }\end{array}$ & No \\
\hline Murugan [24] & Enterovirus & Survived & Yes \\
\hline Hornung [15] & Enterovirus & Survived & Yes \\
\hline Hu [17] & Coxsackie B virus & Survived & Yes \\
\hline Garel [13] & Coxsackie B virus & Survived & Yes \\
\hline Lehoullier [21] & Coxsackie B virus & Survived & Yes \\
\hline Total & & $3 / 13$ died & 5 suggested MI \\
\hline
\end{tabular}

will show thin, fibrotic myocardium caused by infarction with compensatory hypertrophy in the noninfarcted regions. More global abnormalities are found in myocarditis. However, these differences in remodeling can only be observed during the course of several months.

Additional diagnostics are restricted. Endomyocardial biopsy remains the "gold standard" for diagnosing myocarditis and will show inflammatory infiltrate in direct association with myocyte necrosis. Its use in infants is uncommon because it is an invasive procedure, and falsenegative results are possible when inflammation is focal or patchy [5]. Coronary catheterisation or perfusion scan to detect coronary occlusion are not suitable for preterm or low-birth-weight infants. The same applies for magnetic
Table 4 ECG findings significant for MI in children

Wide Q waves ( $>35 \mathrm{~m} \mathrm{~s}$ ): particularly in I, aVL, V5, and V6 but any lead other than aVR

ST segment changes $>2 \mathrm{~mm}$ : elevation in any lead, especially in the presence of reciprocal changes and ST depression in V1-V3

Ventricular arrhythmias calculated as QTc $>0.48$

resonance imaging (MRI) under narcosis, which can be used in myocarditis, which will show increased cardiac signal and enhancement of contrast in the myocardium [2]. In our patient, no abnormal anatomy of heart or coronary arteries, nor signs of thromboembolic events, were found as the cause for MI. Positive rectal and sputum cultures for Coxsackie B virus and findings at follow-up echocardiography suggest myocarditis as the precipitating condition. Additional diagnostic tools (MRI, coronary catheterization, perfusion scan) could not be performed at the onset of symptoms because of prematurity and low birth weight of the child. Unfortunately, additional diagnostic procedures were again not considered during follow-up. At autopsy, regional pattern of scarring was consistent with MI. No signs of active myocarditis were found. The presence of subendocardial elastosis might be suggestive of past viral myocarditis [30]. The signs for (venous) pulmonary hypertension found at autopsy are consistent with longstanding left-ventricular failure. 
Therapy and Prognosis

Recognizing the cause for cardiac dysfunction is important to optimize therapy. Aggressive cardiac support seems to be life saving and can be given by pharmacotherapy (antiarrhythmics, diuretics, inotropes, afterload-decreasing agents) and extracorporal membrane oxygenation. Other supportive measures include pain relief, oxygen therapy, and parenteral feeding to protect the ischemic gut. In contrast to possible therapeutic interventions in adult MI (thrombolysis, percutaneous transluminal coronary angioplasty), few options exist for neonatal MI. Thrombolysis was performed in two case reports of neonatal MI, but both attempts were unsuccessful, and the patients died [1, 32]. Review of previous case reports of neonatal MI show that mortality is high, especially when caused by a thromboembolic event. However, this statement should be interpreted with caution because diagnosis is almost always determined by autopsy. Prognosis of myocarditis appears to be better, but dilated cardiomyopathy is a common complication. When enteroviral myocarditis is suspected, few therapeutic options are available in the acute phase of presentation. Immunoglobulin infusions might improve the outcome of enteroviral disease in neonates, but evidence is lacking [25]. Antiviral therapy with pleconaril (preventing exposure of viral RNA) should be considered but currently remains an experimental therapy [25].

\section{Conclusion}

We presented a preterm infant who suffered of neonatal myocardial infarction possibly precipitated by enteroviral myocarditis. It remains uncertain whether these two disorders are truly related to each other. An overlap in clinical presentation and restrictions in additional diagnostics in neonates makes it hard to differentiate. When enteroviral myocarditis is suspected, immunoglobulins and antiviral therapy should be considered although experience in neonates is limited. Aggressive supportive measures are always necessary in neonatal cardiac dysfunction because they can be life saving.

Open Access This article is distributed under the terms of the Creative Commons Attribution Noncommercial License which permits any noncommercial use, distribution, and reproduction in any medium, provided the original author(s) and source are credited.

\section{References}

1. Abdurrahman L, Schwartz S, Beekman R III (1999) Thrombotic occlusion of the main stem of the left coronary artery in a neonate. Cardiol Young 9:189-191
2. Akkad MZ, O'Connell JB (2003) Myocarditis. In: Crawford MH (ed) Current diagnosis and treatment in cardiology, 2nd edn. McGraw Hill, New York

3. Arthur A, Cotton D, Evans R et al (1968) Myocardial infarction in a newborn infant. J Pediatr 13:110-114

4. Baldew IM, Hess J (1984) Myocardinfarct bij een pasgeborene. T. Kindergeneesk. 52:107-109

5. Baughman KL (2006) Diagnosis of myocarditis. Circulation 113:593-595

6. Bernstein D, Finkbeiner WE, Soifer S et al (1986) Perinatal myocardial infarction: a case report and review of the literature. Pediatr Cardiol 6:313-317

7. Berry C (1970) Myocardial infarction in a neonate. Br Heart J 32:412-415

8. Boulton J, Henry R, Roddick LG et al (1991) Survival after neonatal myocardial infarction. Pediatrics 88:145-150

9. Burch GE, Shewey LL (1976) Viral coronary arteritis and myocardial infarction. Am Heart J 92:11-14

10. Fagan LF, Thurmann M, LoPicollo VF et al (1966) Myocardial infarction in the perinatal period with long-term survival. J Pediatr 69:378-382

11. Ferns S, Khan M, Firmin R et al (2009) Neonatal myocardial infarction and the role of extracorporal membrane oxygenation. Arch Dis Child Fetal Neonatal Ed 94:54-57

12. Fletcher M, Meyer M, Kirkpatrick S et al (1976) Myocardial infarction associated with umbilical cord hematoma. J Pediatr 89:806-807

13. Garel D, Wood C, Bader B et al (1986) Infarctus du myocarde neonatal associe a une infection materno-foetale e virus Coxsackie B4. Arch Fr Pediatr 43:495-496

14. Gault MH, Usher R (1960) Coronary thrombosis with myocardial infarction in a newborn infant. Clinical, electrocardiographic and post-mortem findings. N Eng J Med 25:379-382

15. Hornung TS, Bernard EJ, Howman-Giles RB et al (1999) Myocardial infarction complicating neonatal enterovirus myocarditis. J Paediatr Child Health 35:309-312

16. Hruda J, van de Wal HJCM, Brouwers HAA et al (1995) Survival of a neonate after myocardial infarction complicated by late mitral regurgitation. Pediatr Cardiol 16:131-132

17. Hu WL, Lu JH, Meng L, Hwang B (1998) Neonatal myocardial infarction: a case report. Chin Med J 61:110-115

18. Iannone LA, Durita G, McCarty RJ (1975) Myocardial infarction in the newborn: a case report complicated by cardiogenic shock and associated with normal coronary arteries. Am Heart J 89:232-235

19. Inwald D, Franklin O, Cubitt D et al (2004) Enterovirus myocarditis as a cause of neonatal collapse. Arch Dis Child Fetal Neonatal Ed 89:461-462

20. Kilbride H, Way GL, Merenstein GB et al (1980) Myocardial infarction in the neonate with normal heart and coronary arteries. Am J Dis Child 134:759-762

21. Lehoullier PF, Bowers PN, Harris JP (1996) Cardiology casebook. Coxsackie virus B myocarditis presenting as a myocardial infarction in a newborn infant. J Perinatol 16:403-405

22. Lucas VW Jr, Burchfield DJ, Donelly WH Jr (1994) Multiple coronary thromboemboli and myocardial infarction in a newborn infant. J Perinatol 14:145-149

23. Morgan JM, Gray HH, Pillai RG (1990) Coronary arterial occlusion and myocardial infarction in acute myocarditis. Int J Cardiol 26:226-229

24. Murugan SJ, Gnanapragasam J, Vettukattil J (2002) Acute myocardial infarction in the neonatal period. Cardiol Young 12:411-413

25. Nathan M, Walsh R, Hardin J et al (2008) Enteroviral sepsis and ischemic cardiomyopathy in a neonate: case report and review of literature. ASAIO J 54:554-555 
26. Reich ND, Campbell R (1998) Myocardial infarction in children. Am J Emerg Med 16:296-303

27. Saker DM, Walsh-Sukys M, Spector M et al (1977) Cardiac recovery and survival after neonatal myocardial infarction. Pediatr Cardiol 18:139-142

28. Sandhyamani S, Chopra P (1982) Acute myocardial infarction in the neonate. Indian J Med Res. 75:820-826

29. Sapire DW, Markowitz R, Valdes-Dapena M et al (1977) Thrombosis of the left coronary artery in a newborn infant. J Pediatr 90:957-959

30. Schryer M, Karnauchow PN (1994) Sudden death in infancy, childhood, and adolescence. Am Heart J 88:557-565
31. Takeuchi M, Tomoko S, Masahiro N et al (2005) Neonatal myocardial infarction due to thrombotic occlusion. J Matern Fetal Neonatal Med 19:121-123

32. Tillett A, Hartley B, Simpson J (2001) Paradoxical embolism causing fatal myocardial infarction in a newborn infant. Arch Dis Child Fetal Neonatal Ed 85:137-138

33. Tometzki AJ, Pollock JC, Wilson N et al (1996) Role of ECMO in neonatal myocardial infarction. Arch Dis Child Fetal Ed 74:143-144

34. Van der Hauwert LG, Loos MC, Verhaeghe LK (1967) Myocardial infarction during exchange transfustion in a newborn infant. J Pediatr 70:745-750 